\title{
Meta kaolin -The Best Material for Replacement of Cement in Concrete
}

\author{
M.Narmatha ${ }^{1}$, Dr.T.Felixkala ${ }^{2}$ \\ ${ }^{\text {I}(R e s e a r c h ~ S c h o l a r, ~ D r . M g r ~ E d u c a t i o n a l ~ R e s e a r c h ~ I n s t i t u t e ~ U n i v e r s i t y, ~ C h e n n a i, ~ 600095, ~ I n d i a ~}$ \\ 2( Asso.Prof,. HOD., Dr.Mgr Educational Research Institute University, Chennai, 600095, India
}

\begin{abstract}
Cement concrete is the most extensively used construction material. Maintenance and repair of concrete structures is a growing problem involving significant expenditure. As a result carried out worldwide, it has been made possible to process the material to satisfy more stringent performance requirements, especially long-term durability. HPC is the latest development in concrete. It has become very popular and is being used in many prestigious projects such as Nuclear power projects, flyovers multi-storeyed buildings. When using $H P C$, the addition of supplementary materials in cement has dramatically increased along with the development of concrete industry, due to the consideration of cost saving, energy saving, environmental concerns both in terms of damage caused by the extraction of raw materials and carbon dioxide emission during cement manufacture have brought pressures to reduce cement consumption. Metakaolin looks to be a promising supplementary cementitious material for high performance concrete. Properties of concrete with metakaolin is mostly preferred additives in high performance concrete. A possible lower cost, due to large availability in our country itself may be advantages to metakaolin usage in HPC. The substitution proportion of metakaolin is to be used was 5\%,10\%, 15\%, 20\% by the weight of cement. To make this cubes and cylinders to determine the strength and durability of concrete of it. The results indicate that the replacing mix upto till last percent has to noted and effect on strength in comparing with mixer without metakaolin.
\end{abstract}

Keywords: Metakaolin, Concrete mix, Compressive strength, Split Tensile strength, Flexural strength.

\section{Introduction}

Metakaolin is a pozzolanic additive/product which can provide many specific features. Metakaolin is available in many different varieties and qualities. The purity will define the binding capacity or free lime. Some of them also provide special reactivity. Metakaolin is a valuable admixture for concrete and or cement applications. Usually $8 \%$ - 20\% (by weight) of Portland cement replaced by metakaolin. Such a concrete exhibits favourable engineering properties. The pozzolanic reaction starts soon and continues between 7 to 28 days. For the preliminary investigation, metakaolin and cement was subjected to physical and chemical analyses to determine whether they are in compliance with the standard use. The experimental program was designed to investigate metakaolin as a partial replacement with cement was done at $5 \%, 10 \%$, $15 \%, 20 \%$. The specimen was casted with M60 grade of concrete with different replacement levels of metakaolin.

\subsection{Literature Review}

Jian Tong Ding (2002) investigated the MK or SK on the workability, strength, shrinkage and resistance to chloride penetration of concrete were investigated and compared in this study. For the given mixture proportions, MK offers better workability than does SF. As the replaylcement level was increased, the strength of the MK - modified concrete increased at all ages. The increase in the strength was similar to that of the SF - modified concrete. The incorporation of the both MK and SF in concrete can reduce the free drying the free drying shrinkage and restrained shrinkage cracking width. The initial cracking appeared earlier in the SFand MK- in concrete can reduce the chloride diffusion rate significantly, with the SF concrete performing somewhat better.

Nova John (2013) investigated the cement replacement levels were 5\%,10\%,15\%,20\% by weight for metakaolin. The strength of all metakaolin admixed concrete mixes over shoot the strength development of concrete. Mix with $15 \%$ metakaolin is superior to all other mixes. The increase in metakaolin content improves the compressive strength, split tensile strength and flexural strength upto $15 \%$ replacement. The result encourages the use of metakaolin, as pozzolanic material for partial cement replacement in producing high strength concrete. The inclusion of metakaolin results in faster early age strength development of concrete. The utilization of supplementary cementitious material like metakaolin concrete can compensate for environmental, technical and economic issues caused by cement production. 
Dhinakaran (2012) studied the strength increases by MK concrete is effective only at the early age of concrete and in the long term the strength increase is only marginal. The increase in compressive strength for MK concrete was greater especially at higher water cement ratios (i.e., 0.4 and 0.5 ) and hence more suitable for higher w/cm ratios. From the studies an optimum percentage of MK was found to be $10 \%$ for all $\mathrm{w} / \mathrm{cm}$ ratios except for 0.32 and for 0.32 it was $15 \%$. MK concrete higher increase in strength at early ages beyond 28 days it was found to be less than $10 \%$. The maximum compressive strength of $59.25 \mathrm{~N} / \mathrm{mm} 2$ was observed at $0.4 \mathrm{w} / \mathrm{cm}$ with $10 \% \mathrm{MK}$. Addition of MK reduced the $\mathrm{pH}$ values, but the reduction is insignificant, since the $\mathrm{pH}$ values are still above 11.5, which will be helpful for maintaining the steel in a passive state itself. The depth of penetration of chloride ions for MK concrete is much lesser than control concrete. The minimum rate of reduction of chloride penetration depth for MK admixed concrete were arrived as 78\%, 38\%, 25\% and $25 \%$ for $\mathrm{w} / \mathrm{cm}$ ratios $0.32,0.35,0.40$ and 0.50 respectively. The maximum rate of reduction was observed as $95 \%$ for 0.32 and 0.3 ratios.

Shelorkar ajay (2013) observed that the compressive strength of Metakaolin based HGC increases with the increase in percentage of Metakaolin. The variations of compressive strength of HGC with different Metakaolin content of $4 \%, 6 \%$ and $8 \%$. As the Metakaolin increases from $4 \%$ to $8 \%$ the compressive strength increases about 9.23 MPa for $4 \%$ Metakaolin, $12.98 \mathrm{MPa}$ for $6 \%$ Metakaolin and $20.87 \mathrm{MPa}$ for $8 \%$ Metakaolin. The increase in compressive strength due to the addition of Metakaolin is due to pozzolanic activity. The compressive strength of HGC increases by $10.13 \%, 14.24 \%$ and $22.90 \%$ due to addition of Metakaolin content of $4 \%, 6 \%$ and $8 \%$ respectively in comparison with control concrete specimens of HGC. The variation of RCPT values in HGC for different proportions of Metakaolin blended concrete. It has been observed that as the percentage of Metakaolin increase the permeability of concrete decreases. Also, it was observed that values of rapid chloride permeability of HGC decrease up to 1450 coulombs, 1548.67 coulombs and 1684.70 coulombs for $4 \%, 6 \%$ and $8 \%$ of metakaolin respectively in comparison to control concrete specimens. The percentage reduction in permeability values in coulombs was $48.57 \%, 51.88 \%$ and $56.43 \%$ for Metakaolin content of $4 \%, 6 \%$ and $8 \%$ respectively.

Patil (2012) studied the compressive strength of concrete increases with increase in HRM content up to 7.5\%. Thereafter there is slight decline in strength for $10 \%, 12 \%$ and $15 \%$ due excess amount of HRM which reduces the $\mathrm{w} / \mathrm{b}$ ratio and delay pozzolanic activity. The higher strength in case of $7.5 \%$ addition is due to sufficient amount of HRM available to react with calcium hydroxide which accelerates hydration of cement and forms C-S-H gel. The 7.5\% addition of high reactivity metakaolin in cement is the optimum percentage enhancing the compressive strength at 28 days by $7.73 \%$ when compared with the control mix specimen. The $7.5 \%$ addition of high reactivity metakaolin in cement is enhanced the resistance to chloride attack. The compressive strength of concrete incorporated with $7.5 \%$ HRM is reduced only by $3.85 \%$ as compared with the reduction of strength of control mix specimen is by $4.88 \%$. The $7.5 \%$ addition of high reactivity metakaolin in cement is also enhanced the resistance to sulfate attack. The compressive strength of concrete incorporated with $7.5 \%$ HRM is reduced only by $6.01 \%$ as compared with the reduction of strength of control mix specimen by 9.29\%. The present study deals with the compressive strength, split tensile strength and flexural strength for cement replacement by metakaolin based concrete.

\section{Material Used}

2.1 Cement: OPC of 53 Grade confirming to IS:12269-1987 was used in the investigation. The specific gravity of cement was 3.10

2.2 Coarse Aggregate: Crushed stone metal with a maximum size of $20 \mathrm{~mm}$ from a local source having the specific gravity of 2.7 conforming IS383-1970 was used.

2.3 Fine Aggregate: Locally available river sand passing through $4.75 \mathrm{~mm}$ IS sieve conforming to grading zoneII of IS383-1970 was used. The specific gravity of fine aggregate was 2.54 .

\subsection{Meta kaolin}

Meta kaolin is not a by-product. I $\mathrm{t}$ is obtained by the calcinations of pure or refined Kaolinite clay at a temperature between $650^{\circ} \mathrm{C}$ and $850^{\circ} \mathrm{C}$, followed by grinding to achieve a finesse of $700-900 \mathrm{~m}^{2} / \mathrm{kg}$. It is a high quality pozzolonic material, which is blended with cement in order to improve the durability of concrete. When used in concrete it will fill the void space between cement particles resulting in a more impermeable concrete.

Meta kaolin, is a relatively new material in the concrete industry, is effective in increasing strength, reducing sulphate attack and improving air-void network. Pozzolanic reactions change the microstructure of concrete and chemistry of hydration products by consuming the released calcium hydroxide $(\mathrm{CH})$ and production of additional calcium silicate hydrate (C-S-H), resulting in an increased strength and reduced porosity and therefore improved durability. The formation and properties of Meta kaolin are shown in below. The specimen kept immerse in water for 7 and 28days. The chemical content of meta kaolin presented in Table 1 . 


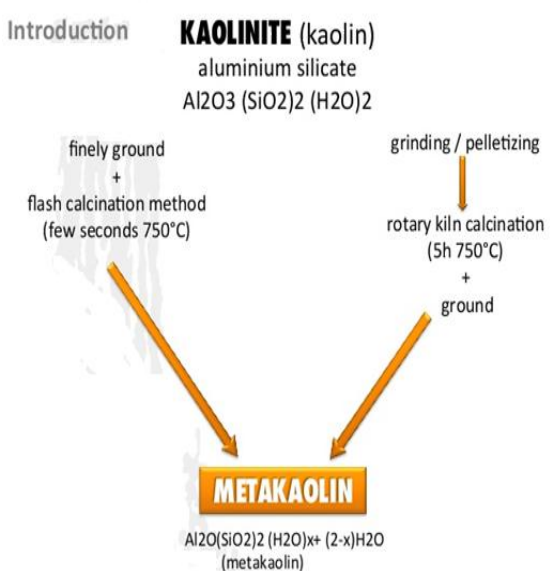

Fig.1 Formation of Matakaolin

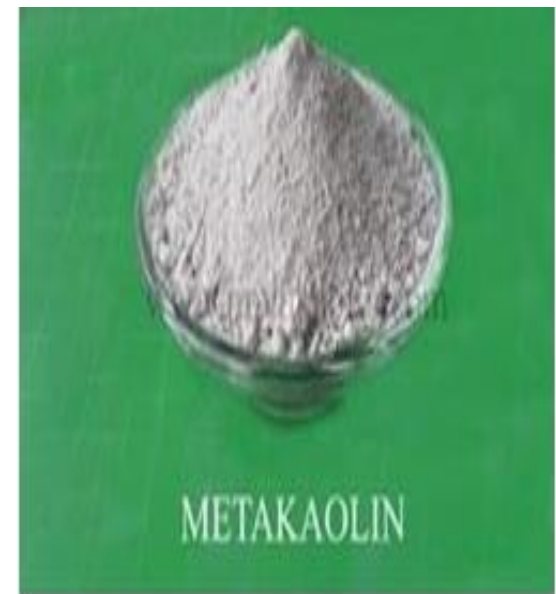

Fig.2 Appearance of Metakaolin

Table 1 Properties of Cement and Metakaolin

\begin{tabular}{|l|l|l|}
\hline Chemical composition & Cement \% & Metakaolin \% \\
\hline Silica $\left(\mathrm{SiO}_{2}\right)$ & & \\
\hline Alumina $\mathrm{Al}_{2} \mathrm{O}_{3}$ & 34 & 54.3 \\
\hline Calcium oxide $\mathrm{CaO}$ & 5.5 & 38.3 \\
\hline Ferric oxide Calcium oxide $\left(\mathrm{Fe}_{2} \mathrm{O}_{3}\right)$ & 63 & 0.39 \\
\hline Magnesium oxide $(\mathrm{MgO})$ & 4.4 & 4.28 \\
\hline Potassium oxide $\left(\mathrm{K}_{2} \mathrm{O}\right)$ & 1.26 & 0.08 \\
\hline Sulphuric anhydride $\left(\mathrm{SO}_{4}\right)$ & 0.48 & 0.50 \\
\hline LOI & 1.92 & 0.22 \\
\hline Specific gravity & 1.3 & 0.68 \\
\hline Physical Form & 3.15 & 2.5 \\
\hline Colour & Fine Powder & Powder \\
\hline & Grey & Off white \\
\hline
\end{tabular}

\subsection{Super Plasticizer}

Poly-carboxylate Ether Super plasticizer obtained from Chemcon tech SYS was used .It conforms to IS $9103-1999$ and its specific gravity of 1.2.

\subsection{Water}

Fresh portable water is free from concentration of acid and organic substance is used for mixing the concrete and curing.

\subsection{Mix Proportions}

Trial mixtures were prepared to obtain target strength more than $60 \mathrm{MPa}$ for the control mixture at 28 days and the w/b ratio for all the mixtures were kept at 0.32 . The details of the mixture (MK0,MK5, MK10, and MK15,20) were employed to examine the influence of low w/b ratio on concretes containing MK on the mechanical and durability properties. The slump of fresh concrete found as 105 to $110 \mathrm{~mm}$. The mix proportions for conventional and volume based partial replacement OPC by Metakaolin presented in Table 2.

Table 2 Mix proportion of concrete

\begin{tabular}{|l|l|l|l|l|l|}
\hline Ingredients & OPC 0\%MK & $\mathbf{5 \%}$ MK & $\mathbf{1 0 \%}$ MK & $\mathbf{1 5 \%}$ MK & $\mathbf{2 0 \%}$ MK \\
\hline Cement & 510 & 485 & 460 & 435 & 410 \\
\hline Metakaolin & 0 & 25 & 50 & 75 & 100 \\
\hline Fine Aggregates & 806 & 806 & 806 & 806 & 806 \\
\hline $\begin{array}{l}\text { Course Agg. } \\
\text { 20mm to 4.75mm }\end{array}$ & 972 & 972 & 972 & 972 & \\
\hline Superplasticizer & 3.0 & & & & 972 \\
\hline Slump (mm) & 120 & 3.25 & 3.6 & 3.8 & 4.0 \\
\hline Water & 162 & 110 & 115 & 105 & 100 \\
\hline
\end{tabular}




\subsection{Casting of Specimens}

\section{Experimental Program}

The test program considered the cast and testing of concrete specimens of cube $(150 \mathrm{~mm})$ and (150x300mm). The specimen was cast M60 grade concrete using OPC, Natural River sand and crushed stone $(20 \mathrm{~mm} 4.75 \mathrm{~mm})$ with Metakaolin. Each three numbers of specimens made to take the average value. The Specimens demoulded after $24 \mathrm{hrs}$. The specimens were allowed to the curing periods.

\subsection{Testing of Specimen}

Testing of specimen was shown in Fig 3.1. The Compressive Strength, Split Tensile Strength and Flexure Strength of test values were presented in table 3, 4, and 5.

\subsubsection{Compressive Strength}

For each mix, twenty four number of cubes of size $150 \mathrm{~mm}$ were cast (7days and 28days) and tested using Compression Testing Machine(CTM). The specimen placed on the platform of the CTM. The load applied gradually until the failure stage. The ultimate load noted and calculated the compressive strength of corresponding specimen.

\subsubsection{Split Tensile Strength}

For each mix, twelve numbers of cylinders of size $300 \times 600 \mathrm{~mm}$ cast and tested in CTM.The specimen placed perpendicular to normal axis on the platform of the CTM. The load applied gradually until the failure stage.

\subsubsection{Flexural Strength}

For each mix, totally twelve number of prism of size 100x100x500mm cast and tested in Flexural Testing Machine(FTM). The specimen of prism placed horizontallyon the platform of the FTM. The ultimate load noted and calculated the flexural strength of corresponding specimen.

\section{Results And Discussion}

The test results of concrete specimen discussed as below:

\subsection{Compressive Strength}

The Compressive Strength compared to control specimen with various percentages of Metakaolin. Compressive Strength results of specimens presented in Table 3. The seven day Compressive Strength varied between 45 and 55MPa. The 28 day strength varied between 61 and 73MPa. The 20\% replacement MK mixture exhibited lower strengths comparatively than the other MK percentages. All the concrete s including the control achieved their target strength of 60MPa at 28 days and all the concretes achieved strength of more than $70 \mathrm{MPa}$. Fig. 3 presents the relation between Compressive Strength and MK percentages at 7 and 28 days. The highest for the MK15 mixtures achieving strength of 72.7MPa at 28days. This clearly shows the replacement level of $15 \%$ was the optimum Compressive Strength is concerned.

After 28 days the compressive strength for MK 5\% increases in 4.36\%, [(64.6/61.9x100)-100] when compared to control specimen. The compressive strength for $10 \%, 15 \%$ and $20 \%$ increases in $13.73 \%, 17.45 \%$ and $12.44 \%$ respectively. MK $15 \%$ increases in higher strength, when compared to all other mixes. But MK $20 \%$ decreases in $4.26 \%$ from MK 15\%. So MK 15\% is the best proportion for add in cement.

Table 3 Compressive Strength in MPa

\begin{tabular}{|c|c|c|c|c|c|c|c|c|c|c|c|c|c|c|c|}
\hline \multirow{3}{*}{$\begin{array}{l}\text { Age of test } \\
7 \text { day cube } \\
\text { strength }\end{array}$} & \multicolumn{3}{|c|}{ Pure OPC } & \multicolumn{3}{|c|}{ 5\% Metakaoline } & \multicolumn{3}{|c|}{$10 \%$ Metakaoline } & \multicolumn{3}{|c|}{ 15\% Metakaoline } & \multicolumn{3}{|c|}{$20 \%$ Metakaoline } \\
\hline & 43.9 & 47.4 & 44.0 & 50.2 & 51.5 & 50.9 & 52.9 & 52.3 & 50.4 & 52.8 & 56.8 & 54.9 & 52.1 & 51.9 & 50.2 \\
\hline & \multicolumn{3}{|l|}{45.1} & \multicolumn{3}{|l|}{50.9} & \multicolumn{3}{|l|}{51.9} & \multicolumn{3}{|l|}{54.8} & \multicolumn{3}{|l|}{51.4} \\
\hline \multirow{2}{*}{$\begin{array}{l}28 \text { day cube } \\
\text { strength }\end{array}$} & 63.1 & 61.1 & 61.6 & 63.5 & 67.5 & 62.6 & 67.5 & 72.4 & 71.4 & 72.8 & 71.1 & 74.2 & 67.2 & 70.2 & 71.6 \\
\hline & \multicolumn{3}{|l|}{61.9} & \multicolumn{3}{|l|}{64.6} & \multicolumn{3}{|l|}{70.4} & \multicolumn{3}{|l|}{72.7} & \multicolumn{3}{|l|}{69.6} \\
\hline $\begin{array}{l}\% \text { of Increasing } \\
\text { from MK0\% }\end{array}$ & \multicolumn{3}{|l|}{-} & \multicolumn{3}{|c|}{$4.36 \%$} & \multicolumn{3}{|c|}{$13.73 \%$} & \multicolumn{3}{|c|}{$17.45 \%$} & \multicolumn{3}{|c|}{$12.44 \%$} \\
\hline
\end{tabular}




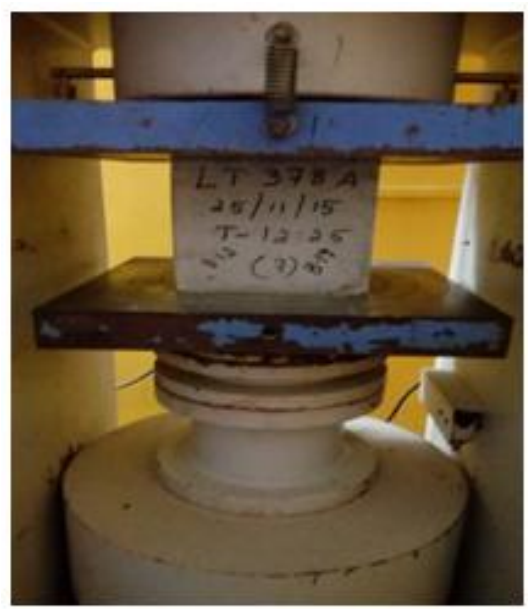

Fig.3 Compression testing

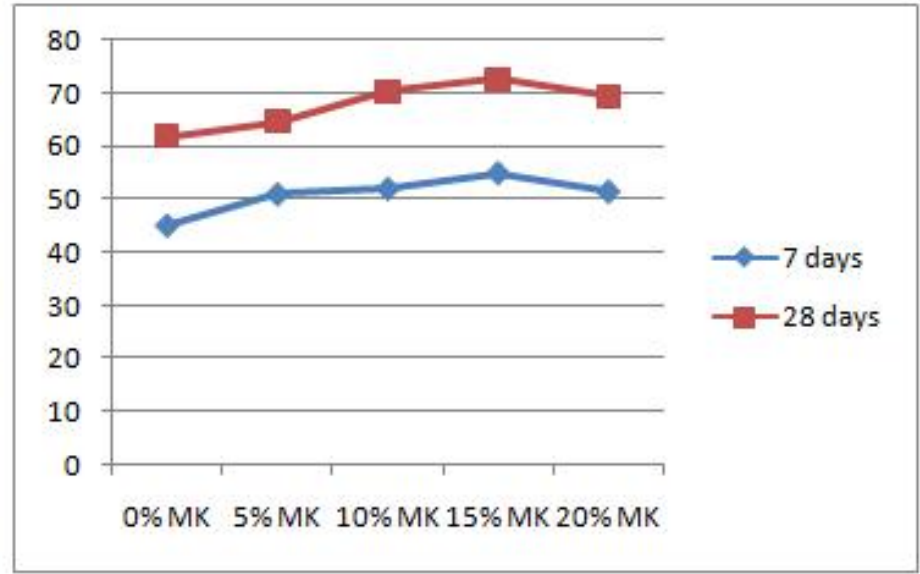

Fig. 4. Variation of Compressive Strength

\subsection{Split Tensile Strength}

From the results Split Tensile Strength also exhibited the highest strength at MK15 mixture. The Split Tensile strength for MK 5\% increases in $8 . .82 \%$, when compared to control specimen. The Split Tensile strength for MK 10\%, 15\% and 20\% increases in $14.70 \%, 20.56 \%$ and $11.76 \%$ respectively. MK $15 \%$ increases in higher strength, when compared to all other mixes. But MK 20\% decreases in 7.31\% from MK15\%. So MK $15 \%$ is the best proportion for add in cement. The split tensile strength and various mix concrete test values are presents in Table 4 and variation of split tensile strength shown in Fig.4

Table 4 Split Tensile Strength in Mpa

\begin{tabular}{|c|c|c|c|c|c|c|c|c|c|c|c|c|c|c|c|}
\hline \multirow{3}{*}{$\begin{array}{l}\text { Age of test } \\
28 \text { day split } \\
\text { tensile strength }\end{array}$} & \multicolumn{3}{|c|}{ 0\% Metakaoline } & \multicolumn{3}{|c|}{$5 \%$ Metakaoline } & \multicolumn{3}{|c|}{ 10\% Metakaoline } & \multicolumn{3}{|c|}{ 15\% Metakaoline } & \multicolumn{3}{|c|}{$20 \%$ Metakaoline } \\
\hline & 3.3 & 3.2 & 3.6 & 3.5 & 3.8 & 3.7 & 4.0 & 3.7 & 4.0 & 4.0 & 4.3 & 4.2 & 3.9 & 3.6 & 4.0 \\
\hline & \multicolumn{3}{|l|}{3.4} & \multicolumn{3}{|l|}{3.7} & \multicolumn{3}{|l|}{3.9} & \multicolumn{3}{|l|}{4.1} & \multicolumn{3}{|l|}{3.8} \\
\hline $\begin{array}{l}\% \text { of Increasing } \\
\text { from MK } 0 \%\end{array}$ & \multicolumn{3}{|l|}{-} & \multicolumn{3}{|c|}{$8.82 \%$} & \multicolumn{3}{|c|}{$14.7 \%$} & \multicolumn{3}{|c|}{$20.56 \%$} & \multicolumn{3}{|c|}{$11.76 \%$} \\
\hline
\end{tabular}

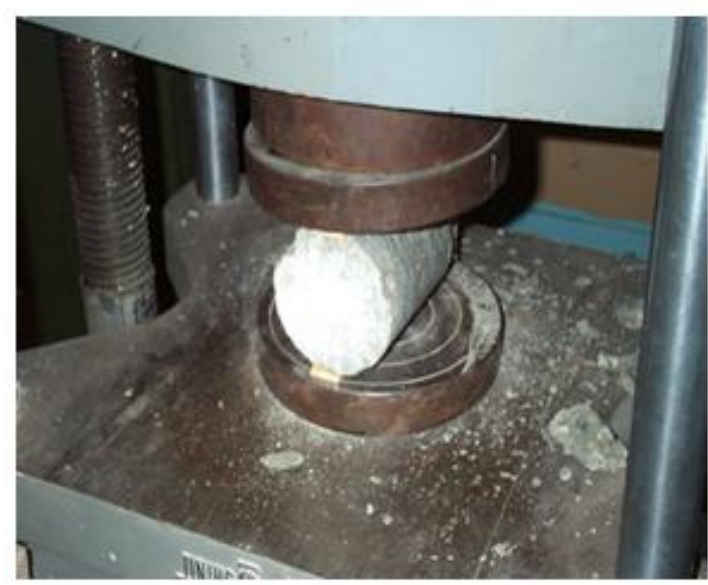

Fig.3 Split Tensile testing

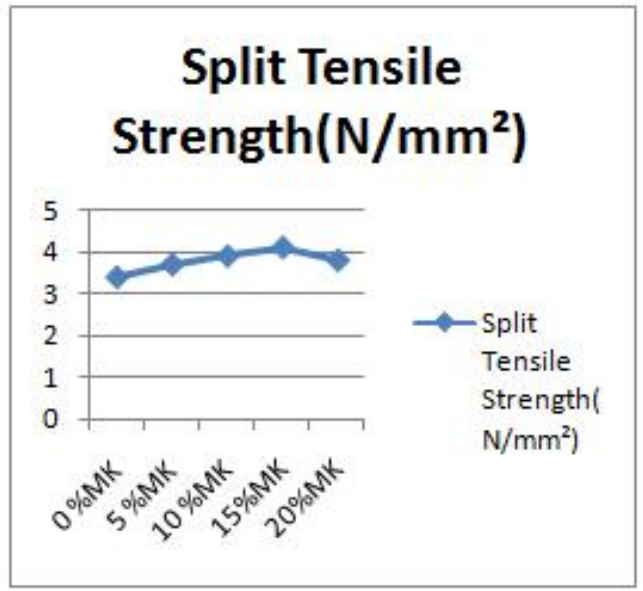

Fig. 4. Variation of Split Tensile Strength

\subsection{Flexural Strength}

The Flexural strength compared to control specimen with various percentages of Metakaolin. When compared to control specimen the Flexural strength for MK5\% increases $4.76 \%$. The Flexural strength for MK $10 \%, 15 \%$ and $20 \%$ increases $11.11 \%, 14.28 \%$ and $7.94 \%$ respectively. MK $15 \%$ gave high flexural strength. But $20 \%$ of MK decreases in $5.55 \%$ from MK15\%. So MK $15 \%$ is the best proportion for add in cement. The Flexural strength and various mix concrete test values are presents in Table 5 and variation of Flexural strength shown in Fig.6. 
Table 5 Flexural Strength in MPa

\begin{tabular}{|c|c|c|c|c|c|c|c|c|c|c|c|c|c|c|c|}
\hline \multirow{3}{*}{$\begin{array}{l}\text { Age of test } \\
28 \text { days Flexural } \\
\text { Strength }\end{array}$} & \multicolumn{3}{|c|}{ Pure OPC } & \multicolumn{3}{|c|}{ 5\% Metakaoline } & \multicolumn{3}{|c|}{$10 \%$ Metakaoline } & \multicolumn{3}{|c|}{ 15\% Metakaoline } & \multicolumn{3}{|c|}{$20 \%$ Metakaoline } \\
\hline & 6.4 & 5.9 & 6.6 & 6.5 & 6.6 & 6.7 & 6.8 & 7.2 & 7.2 & 7.0 & 7.2 & 7.3 & 6.7 & 6.9 & 6.8 \\
\hline & \multicolumn{3}{|l|}{6.3} & \multicolumn{3}{|l|}{6.6} & \multicolumn{3}{|l|}{7.0} & \multicolumn{3}{|l|}{7.2} & \multicolumn{3}{|l|}{6.8} \\
\hline $\begin{array}{l}\% \text { of Increasing } \\
\text { from } \mathrm{MK} 0 \%\end{array}$ & \multicolumn{3}{|l|}{-} & \multicolumn{3}{|c|}{$6.6 \%$} & \multicolumn{3}{|c|}{$11.11 \%$} & \multicolumn{3}{|c|}{$7.2 \%$} & \multicolumn{3}{|c|}{$6.8 \%$} \\
\hline
\end{tabular}

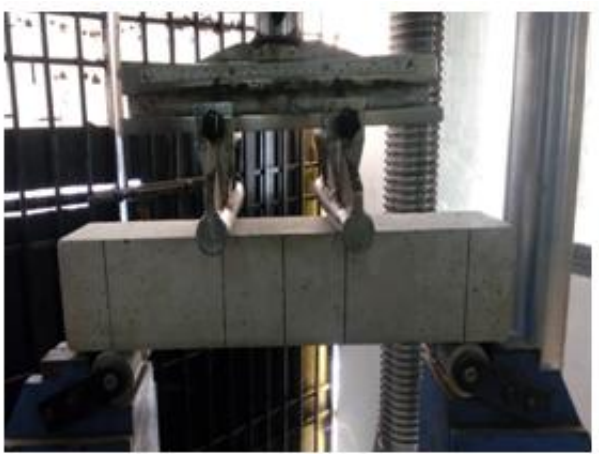

Fig.5 Flexural Strength testing

\section{Flexural strength $\mathrm{N} / \mathrm{mm}^{2}$}

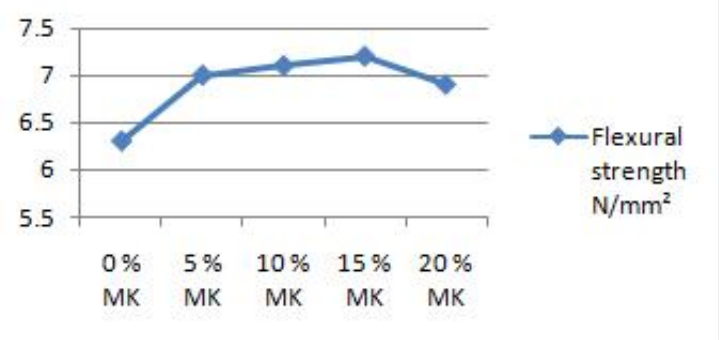

Fig. 6. Variation of Flexural Strength Strength

\section{Conclusions}

From the present investigation on the effect of partial replacement of cement with Metakaolin in concrete, the following conclusions were drawn;

- The strength of all Metakaolin concrete mixes over shoot the strength of OPC.

- $15 \%$ cement replacement by Metakaolin is superior to all other mixes.

- The increase in Metakaolin content improves the compressive strength and split tensile strength up to $15 \%$ cement replacement.

- The results encourage the use of Metakaolin, as a pozzolanic material for partial replacement in producing high performance concrete.

\section{References}

[1]. Sabir B.B, Wild S, Bai J, "Metakaolin and calcined clay as pozzolans for concrete :a review" Cement and concrete composite 23 ,(2001),pp.441-454.

[2]. Jian-Tong Ding and Zongjin Li "Effects of Metakaolin and Silica Fume on Properties of Concrete" ACI Materials Journal/July-August 2002,pp.393-398.

[3]. Badogiannis E, Papadakis V.G., Chaniotakis E, Tsivilis S, "Exploitation of poor Greek kaolins: Strength development of metakaolin concrete and evaluation by means of k-value" Cement and Concrete Research 34 (2004),pp.1035-1041.

[4]. Justice J.M, Kennison L.H, Mohr B.J., Beckwith S.L, McCormick L.E, Wiggins B., Zhang Z.Z, and Kurtis K.E, "Comparison of Two Metakaolins and a Silica Fume Used as Supplementary Cementitious Materials” SP- 228(Volume1\&2) Seventh International Symposium on Utilization of High-Strength/HighPerformance Concrete, June(2005),SP228.

[5]. Naik T.R.Singh, S.S and hossian,M.M (1995),"Properties of high performance concrete systems in corporating large amounts of high lime fly ash; Construction And Building Materials. Vol.9.No 4.Pp.195-204.

[6]. M.B.Kumthekar, G.S.Vyas, N.T.Suryawanshi and M.B.More," Techno-Economical Benefit of Metakaolin Over Microsilica in Developing High Performance Concrete", CE\&CR July 2007,pp. 42-50.

[7]. Dinakar P," High reactivity metakaolin for high strength and high performance concrete", The Indian Concrete Journal, April 2011, pp.28-32 